\title{
RESTRIÇÃO HÍDRICA EM SEMENTES DE JENIPAPO (Genipa americana L.)
}

\author{
Allívia Rouse Ferreira dos Santos², Renata Silva-Mann³ e Robério Anastácio Ferreira ${ }^{3}$
}

\begin{abstract}
RESUMO - O jenipapo, originário da América Latina, pertence à família Rubiaceae e apresenta valor madeireiro e alimentício, sendo explorado sem estratégias de conservação. O objetivo deste trabalho foi avaliar o efeito da restrição hídrica, por meio de duas metodologias, na germinação de sementes de Genipa americana L. A primeira foi realizada com sementes imersas em soluções de polietilenoglicol (PEG 6000) por 18 dias a 0,$0 ;-0,1 ;-0,3$ e - $0,4 \mathrm{MPa}$ à $20^{\circ} \mathrm{C}$, simulando condições de alagamento, e após este período as sementes foram colocadas para germinar em placas de Petri com folhas de papel tipo mata-borrão umedecidas em água. A segunda utilizou os mesmos potenciais osmóticos umedecendo-se os papéis tipo mata-borrão, para simular a restrição hídrica. O delineamento utilizado foi o inteiramente casualizado com 4 repetições de 25 sementes. Para as sementes imersas em soluções de PEG, o potencial -0,3MPa permite condicionamento osmótico, enquanto à -0,4MPa interfere no vigor. Para as sementes embebidas em papel, ocorre redução da germinação em função do tempo, até não se observar eventos para potenciais a partir de -0,3 $\mathrm{MPa}$.
\end{abstract}

Palavras chave: Priming, PEG e Vigor

\section{WATER RESTRICTION IN JENIPAPO SEEDS (Genipa americana L.)}

\begin{abstract}
The jenipapo is a native species from Latin America, belonging to the Rubiaceae family and presents great timber value and alimentary, being exploited without conservation strategies. This study aimed to evaluate the water restriction effect, using two methodologies for the Genipa americana L. seeds germination. The first methodology was performed with immersed seeds in polyethylene glycol solutions (PEG 6000) for 18 days at $0.0,-0.1,-0.3$, and $-0.4 \mathrm{MPa}$ at $20^{\circ} \mathrm{C}$, simulating the flooding conditions. After this period, the seeds were disposed to germinate in Petri dishes with germitest paper, blotter paper type, moistened with water. The second methodology used the same osmotic potential, damping the blotter paper type to simulate the fluid restriction. A completely randomized design was used with four replications of 25 seeds. For the immersed seeds in PEG solutions, the potential -0.3 MPa allowed the osmotic conditioning, while the -0.4 MPa interfered in vigor. In imbibed seeds in paper there was a germination reduction, because the time, until potential events were not observed from -0.3 MPa.
\end{abstract}

Keywords: Priming, PEG and Vigor

\section{INTRODUÇÃO}

A adaptabilidade das plantas em condições de restrição de água é influenciada pela duração e magnitude da restrição, além da variabilidade genética, e das interações genótipo e ambiente, que podem ser desencadeadas em condições de estresse, ou seja, excesso ou deficiência de algum fator do meio ambiente, como água, luz, temperatura, nutrientes, entre outros (ANDRADE e CASALI, 1999).
O entendimento da tolerância das plantas à seca e como explorá-las, principalmente com relação aos problemas de ordem fisiológica ou ecológica, apresenta extrema importância, sobretudo para recuperação de áreas onde há problemas com estresse hídrico por razões climáticas ou condições do tipo de solo.

Esses problemas são comuns em áreas do Semiárido nordestino. O estresse hídrico severo pode levar à diminuição das defesas da planta, reduzindo o

\footnotetext{
${ }^{1}$ Recebido em 03.08.2008 e aceito para publicação em 16.12.2011.

${ }^{2}$ Doutorado em andamento pela Universidade de Santiago de Compostela, USC, Espanha. E-mail: <alliviarouse@hotmail.com>.

${ }^{3}$ Universidade Federal de Sergipe, UFS, Brasil. E-mail: <renatamann@gmail.com> e <raf@ufs.br; >.
} 
crescimento e a fotossíntese. A adaptabilidade e tolerância ao estresse hídrico são estratégias intrínsecas diferentes nas espécies vegetais. Na germinação afeta o alongamento celular e a síntese de parede, e para cada espécie existe um valor de potencial hídrico crítico, abaixo do qual a germinação não ocorre (CARVALHO e CASALI, 1999; CARVALHO, 2005).

Em algumas situações, a restrição hídrica pode funcionar como condicionamento osmótico, também denominado priming, que é uma das técnicas que têm sido utilizadas para acelerar e uniformizar a germinação e também para simular restrição hídrica. Alguns trabalhos têm mostrado efeitos positivos do priming, que são mais evidentes sob condições adversas de campo, como baixa temperatura, estresse hídrico, salinidade e temperatura elevada (BITTENCOURT et al., 2004).

O condicionamento osmótico consiste de hidratação controlada das sementes suficiente para promover atividades pré-metabólicas sem, contudo, permitir a emissão da raiz primária, pois diminui a entrada de água nas sementes, não deixando que estas germinem durante o condicionamento (NASCIMENTO, 2004). Esse condicionamento pode proporcionar a reorganização ou a desestruturação das membranas das sementes, durante o processo de embebição. O efeito sobre essas membranas irá depender de vários fatores, entre eles o produto utilizado na solução osmótica, o tempo de exposição, o método empregado e a concentração desse produto.

O polietilenoglicol (PEG) é um dos produtos utilizados nesse tipo de tratamento, já que tem a vantagem de ser inerte e não penetrar nas sementes. A desvantagem é que não permite aeração uniforme na solução, apresenta certa dificuldade de remoção após o tratamento e é produto de custo elevado. O período de embebição requerido para as sementes varia, dependendo da espécie, temperatura e outros fatores. Períodos muito curtos podem não permitir o sucesso do tratamento, enquanto muito prolongados podem favorecer a germinação durante o tratamento, além de prejudicarem o vigor das sementes (NASCIMENTO, 2004).

O uso do condicionamento osmótico com espécies florestais nativas é ainda muito limitado, e por essa razão são necessárias informações sobre a utilização de técnicas que possibilitem uniformidade na germinação dessas sementes, sob condições adversas, de modo a contribuir com programas de reflorestamento de áreas degradadas ou de recomposição de matas nativas (JELLER e PEREZ, 2003) e também para conhecimento do comportamento das sementes sob restrição hídrica.

Esses conhecimentos são de fundamental importância, pois auxiliam nos estudos para regeneração de áreas degradas e no entendimento sobre estabelecimento das espécies e comportamento quanto à germinação.

O jenipapo destaca-se por ser espécie que ocorre em vários Estados brasileiros, entre eles Sergipe, que desperta a necessidade de estudos, pois vem sendo utilizada em programas de restauração de áreas degradadas pelo Grupo de Restauração da Universidade Federal de Sergipe. A espécie é explorada tanto pelas características madeireiras quanto por seu fruto que possui vários atributos medicinais, alimentícios e cosméticos, o que causa ação extrativista sem nenhum cuidado de preservação e conhecimento da espécie. Os trabalhos encontrados são de aspectos gerais e de fenologia da espécie (UNCTAD, 2005; CRESTANA et al., 1992), produção de mudas (COSTA et al., 2005; FERREIRA et al., 2007) e caracterização dos frutos (SILVA et al., 1998; ANDRADE et al., 2003).

Estudos envolvendo o esclarecimento sobre a tolerância da espécie aos diversos fatores ambientais, com destaque para a restrição hídrica, são de grande valor, pois auxiliam na definição de novas áreas a serem implantadas e da influência dessa restrição como condicionamento osmótico. Assim, o objetivo deste trabalho foi avaliar o efeito da restrição hídrica como fator de condicionamento osmótico diretamente na geminação de sementes de jenipapo.

\section{MATERIAL E MÉTODOS}

O trabalho foi realizado no Laboratório de Tecnologia de Sementes do Departamento de Engenharia Agronômica da Universidade Federal de Sergipe. Foram utilizados frutos de jenipapo procedentes do Município de Divina Pastora, em Sergipe $\left(10^{\circ} 42^{\prime} 13,31^{\prime \prime} \mathrm{S}\right.$ $\left.30^{\circ} 09^{\prime} 38,46^{\prime \prime} \mathrm{O}\right)$, colhidos em novembro de 2007 . Os frutos foram beneficiados com o auxílio de peneira e água corrente. As sementes beneficiadas foram colocadas para secar à sombra por 48 horas. A fim de obter uniformidade, foram selecionadas aquelas quanto à coloração, tamanho e estado de conservação para compor os tratamentos.

Revista Árvore, Viçosa-MG, v.35, n.2, p.213-220, 2011 
As sementes foram condicionadas de duas formas, uma na imersão em soluções de polietilenoglicol (PEG 6000) com potenciais osmóticos de 0,$0 ;-0,1$; -0,3; e -0,4 MPa, por 18 dias a $20^{\circ} \mathrm{C}$, sendo após esse período as sementes colocadas para germinar em placas de Petri com folhas de papel tipo mata-borrão umedecidas com 6 mL de água destilada. A segunda consistiu em dispor as sementes sobre papel tipo mata-borrão umedecido com $6 \mathrm{~mL}$ com soluções de polietilenoglicol (PEG 6000), nos mesmos potenciais anteriormente descritos.

Cada tratamento teve quatro repetições de 25 sementes, perfazendo um total de 100 sementes por tratamento. A constância de temperatura nos testes de germinação realizados foi obtida por meio do uso de incubadora (tipo BOD) a $25^{\circ} \mathrm{C} \pm 2$, sob luz contínua, sendo avaliados por 40 dias. As concentrações de polietilenoglicol (PEG 6000) utilizadas no preparo das soluções dos diferentes potenciais osmóticos foram definidas em razão da temperatura, conforme a equação proposta por Michel e Kaufmann (1973):

$$
\Psi \text { os }=-\left(1,18 \times 10^{-2}\right) \mathrm{C}-\left(1,18 \times 10^{-4}\right) \mathrm{C}^{2}-\left(2,67 \times 10^{-4}\right) \mathrm{CT}
$$
$+\left(8,39 \times 10^{-7}\right) \mathrm{C}^{2} \mathrm{~T}$

em que:

$$
\begin{aligned}
& \text { Yos = potencial osmótico (bar); } \\
& \text { C : concentração (g PEG 6000/L); e } \\
& \text { T : temperatura }\left({ }^{\circ} \mathrm{C}\right) .
\end{aligned}
$$

Após a obtenção dos resultados de germinação, as médias foram comparadas pelo teste de Tukey a 5\% de probabilidade e as análises, avaliadas por regressão pelo programa SISVAR ${ }^{\circledR}$ (FERREIRA, 2000).

As avaliações foram realizadas diariamente por 40 dias, em que foram calculados:

A porcentagem de germinação (\%G) (LABOURIAU e VALADARES, 1976):

$$
\% G=\frac{N}{A} X 100
$$

em que:

\% G = porcentagem de germinação;

$\mathbf{N}=$ número de sementes germinadas; e

$\mathbf{A}=$ número total de sementes colocadas para germinar.
Índice de Velocidade Germinação (IVG) (MAGUIRE, 1962):

$$
I V G=\mathrm{G} 1 / \mathrm{N} 1+\mathrm{G} 2 / \mathrm{N} 2+\cdots+\mathrm{Gn} / \mathrm{Nn}
$$

em que:

IVG = Índice de Velocidade de Germinação;

$\mathrm{G}_{1}, \mathrm{G}_{2}, \mathrm{G}_{\mathrm{n}=}$ número de plântulas germinadas, computadas na primeira, segunda até a última contagem; e $\mathrm{N}_{1}, \mathrm{~N}_{2}, \mathrm{~N}_{\mathrm{n}}=$ número de dias da semeadura à primeira, segunda até a última contagem.

Tempo Médio de Germinação (TMG) (LABOURIAU, 1983):

$$
T M G=\frac{\sum n i . t i}{\sum n i}
$$

em que:

TMG = tempo médio de germinação (dias);

ni = número de sementes germinadas num intervalo de tempo; e

ti = intervalo de tempo de germinação.

Velocidade Média de Germinação (V) (LABOURIAU, 1983):

$$
V=\frac{1}{T M G}
$$

em que:

$\mathrm{V}=$ velocidade média de germinação (sementes/ dia); e

TMG = tempo médio de germinação.

\section{RESULTADOS}

Durante os testes, não foi observada a presença de fungos. Nos tratamentos de simulação de estresse hídrico sobre papel utilizando as soluções de PEG somente na concentração de -0,1 MPa, verificou-se germinação, em que esse tratamento não diferiu da testemunha (0,0 MPa), apresentando apenas diferença na variável IVG. Nas concentrações de -0,3 e -0,4 MPa, não foi notada a emissão de raiz até o último dia de avaliação (aos 40 dias) (Tabela 1).

Quando as sementes foram submetidas à restrição usando imersão em solução de PEG, sendo posteriormente transferidas para a placa de Petri umedecida com água, observou-se que não houve diferença entre os

Revista Árvore, Viçosa-MG, v.35, n.2, p.213-220, 2011 
Tabela 1 - Valores de Germinação (G), Índice de Velocidade (IVG); Tempo Médio (TMG) e Velocidade Média de Germinação (VMG) de sementes de Genipa americana L. sob restrição hídrica utilizando papel embebido com soluções de PEG 6000.

Table 1 - Germination values (G), Germination Speed Index (IVG), Germination Average Time (TMG), and Germination Average Speed (VMG) of Genipa americana L. seeds under water restriction, using soaked paper with PEG 6000 solutions.

\begin{tabular}{ccccc}
\hline Tratamentos $(\mathrm{MPa})$ & G $(\%)$ & IVG & TMG (dia) & VMG \\
\hline 0,0 & $95 \mathrm{a}$ & $1,32 \mathrm{a}$ & $14,70 \mathrm{~b}$ & $0,06 \mathrm{a}$ \\
$-0,1$ & $51,25 \mathrm{a}$ & $0,55 \mathrm{~b}$ & $18,62 \mathrm{a}$ & $0,05 \mathrm{a}$ \\
$-0,3$ & 0,0 & 0,0 & 0,0 & 0,0 \\
$-0,4$ & 0,0 & 0,0 & 0,0 & 0,0 \\
\hline
\end{tabular}

Médias seguidas pela mesma letra não diferem entre si pelo teste de Tukey a 5\% de probabilidade.

Tabela 2 - Valores de Germinação (G), índice de Velocidade (IVG); Tempo Médio (TMG) e Velocidade Média de Germinação (VMG) sementes/dias de Genipa americana L., submetidas ao condicionamento em soluções de PEG 6000 a $20^{\circ} \mathrm{C}$.

Table 2 - Germination values (G), Germination Speed Index (IVG), Germination Average Time, (TMG), and Germination Average Speed (VMG) by seeds/days of Genipa americana L. under priming in PEG 6000 solutions at $20^{\circ} \mathrm{C}$.

\begin{tabular}{ccccc}
\hline Tratamentos $(\mathrm{MPa})$ & G (\%) & IVG & TMG (dia) & VMG \\
\hline 0,0 & $77 \mathrm{a}$ & $1,37 \mathrm{a}$ & $16,98 \mathrm{a}$ & $0,06 \mathrm{a}$ \\
$-0,1$ & $93 \mathrm{a}$ & $1,52 \mathrm{a}$ & $16,96 \mathrm{a}$ & $0,06 \mathrm{a}$ \\
$-0,3$ & $96 \mathrm{a}$ & $1,54 \mathrm{a}$ & $16,65 \mathrm{ab}$ & $0,06 \mathrm{a}$ \\
$-0,4$ & $98 \mathrm{a}$ & $1,58 \mathrm{a}$ & $13,51 \mathrm{~b}$ & $0,07 \mathrm{a}$ \\
\hline
\end{tabular}

Médias seguidas pela mesma letra não diferem entre si pelo teste de Tukey a 5\% de probabilidade.
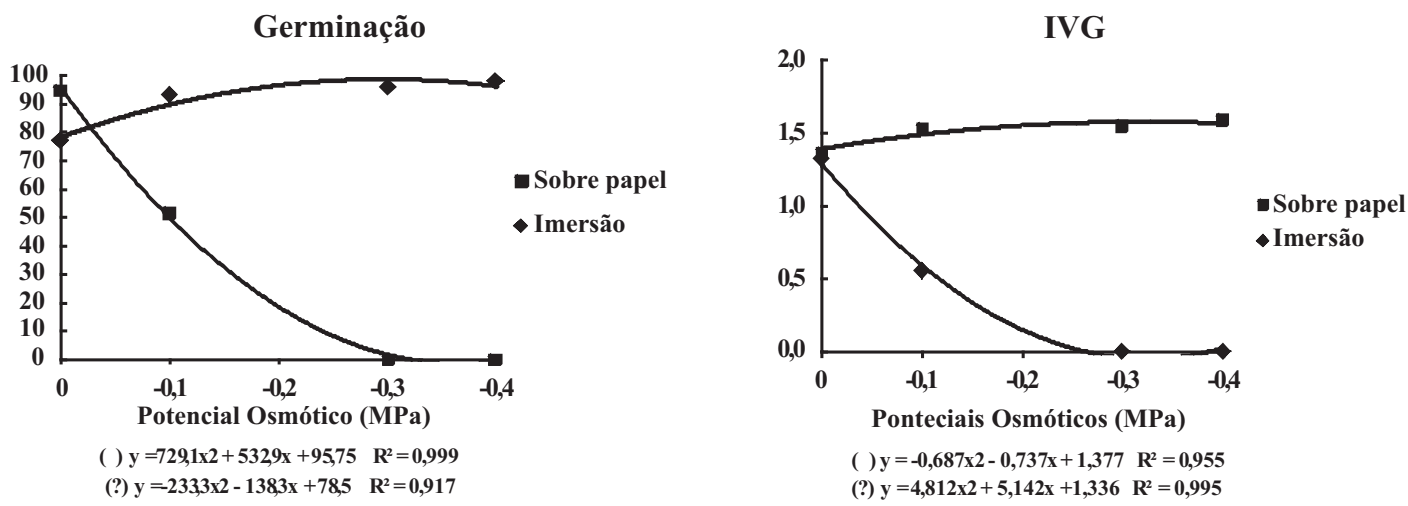

TMG

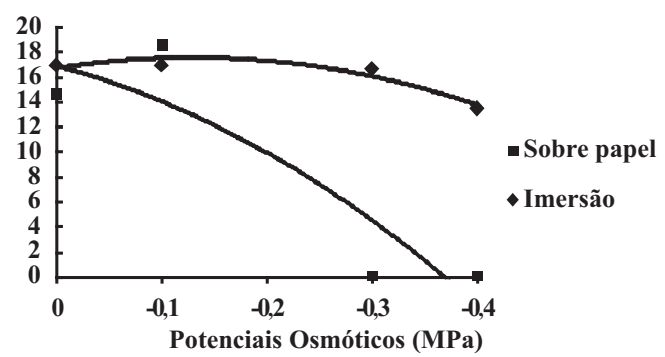

() $y=65,33 x 2+21,88 x+16,95 R^{2}=0,821$ (?) $y=52 \times 2-13,55 x+16,69 \quad R^{2}=0,904$

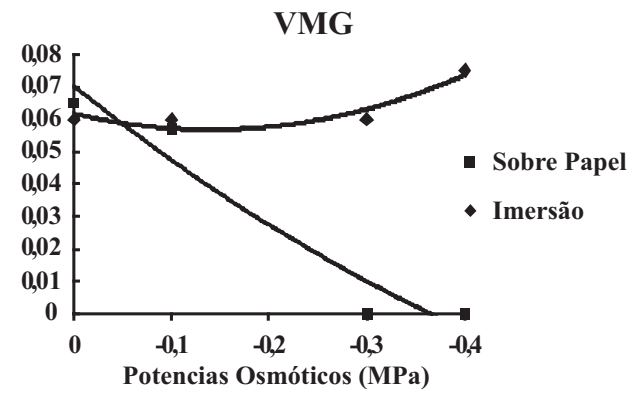

() $y=0,133 \times 2+0,240 x+0,069 R^{2}=0,936$ (?) $y=0,25 x 2+0,07 x+0,061 \quad R^{2}=0,866$

Figura 1 - Comportamento das sementes de jenipapo (Genipa americana L.) submetidas a restrição hídrica sobre papel embebido ( $\square$ ) e sob imersão ( $\downarrow$ ) em diferentes potenciais osmóticos.

Figure 1 - Jenipapo (Genipa americana L.) seeds behavior subjected to water restriction on soaked paper (ם) and under immersion $(\diamond)$ in different osmotic potentials.

Revista Árvore, Viçosa-MG, v.35, n.2, p.213-220, 2011 
tratamentos, nos diferentes potencias osmóticos utilizados, sendo verificado aumento nos tratamentos de 0,0 e -0,3 MPa nas variáveis \%G, IVG e VMG (Tabela 2).

Os resultados deste experimento com ambas as metodologias de restrição empregadas nas sementes de jenipapo, em todas as características avaliadas, comportaram-se de maneira diferenciada, sendo os maiores contrastes detectados nos maiores níveis de potencial osmótico (Figura 1).

Ao analisar a evolução da germinação pelas duas metodologias, notou-se que em cada tratamento, no método usando imersão das sementes, depois dispondo-as sobre papel embebido com água, ocorreu comportamento diferente, havendo comportamento similar até o potencial de -0,3 MPa, depois aconteceu diminuição da germinação no potencial de -0,4 MPa (Figura 2).

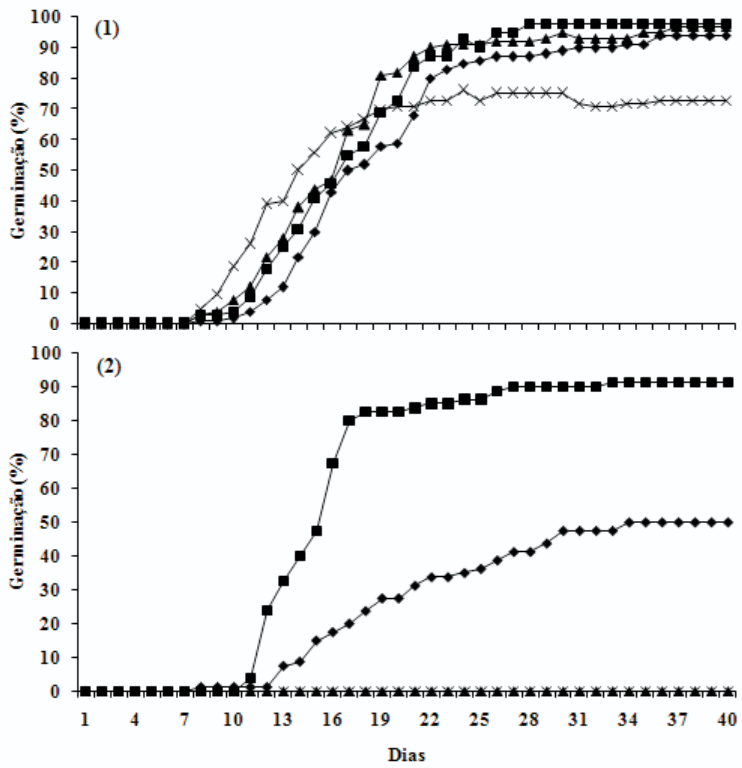

Figura 2 - Evolução da porcentagem de germinação em dias de sementes de Genipa americana L. sob imersão a $20^{\circ} \mathrm{C}$ (1) e sobre papel embebido (2) em diferentes concentrações de PEG 6000: (४) 0,0; ( $\square$ ) - 0,1; (4) - 0,3 e (x) -0,4 MPa.

Figure 2 - Germination percentages evolution by days of Genipa americana $L$. seeds under immersion at $20^{\circ} \mathrm{C} \mathrm{(1)} \mathrm{and} \mathrm{on} \mathrm{soaked} \mathrm{paper} \mathrm{(2)} \mathrm{in} \mathrm{different}$ concentrations of PEG 6000: ( ) 0,0; (ם) 0,$1 ;(\mathbf{\Delta})-0,3$, and $(\mathrm{x})-0,4 \mathrm{MPa}$.

\section{DISCUSSÃO}

A falta da germinação no tratamento sob restrição hídrica em papel, nos potenciais de -0,3 e -0,4 MPa, foi explicada por Fonseca e Perez (2003) ao estudarem estresse hídrico em sementes de Adenanthera pavonina L. Verificaram que nas sementes quando colocadas em contato com determinadas concentrações de soluções aquosas contendo solutos ocorre a embebição de água normalmente, porém o processo cessa quando entra em equilíbrio com o potencial osmótico da solução externa, sem que ocorra a protrusão da raiz. Potenciais suficientemente baixos inibem a expansão da raiz primária, mesmo a semente estando metabolicamente ativa pronta para a germinação e alongamento celular, mesmo após algumas semanas de contato com a solução osmótica.

Já nas sementes imersas nos diferentes potencias de PEG por 18 dias houve aumento nos valores das variáveis analisadas para 0,0 a -0,3 MPa. Isso pode ser explicado pelo benefício, até certo nível, do condicionamento relacionado aos processos de germinação e emergência das plântulas, promovendo a redução no tempo requerido para que esses eventos aconteçam. Resultados semelhantes já foram notificados por Rossetto et al. (1998), em sementes de Beta vulgaris L. submetidas ao condicionamento com água em diferentes tempos, em que esses autores observaram que as sementes condicionadas apresentavam maior produtividade.

Embora o condicionamento osmótico de sementes tenha sido largamente estudado nas últimas duas décadas, ainda existe a necessidade de expandir o conhecimento básico sobre diferentes aspectos relacionados com essa técnica, principalmente para espécies nativas e florestais. No que envolve a praticidade do tratamento, vários aspectos devem ser focalizados, como padronização e uso da metodologia para cada espécie. Entretanto, não se deve criar expectativa em relação à semente condicionada; em algumas espécies e em determinadas condições, a sua utilização poderá ser significativamente benéfica, enquanto em outras situações não (NASCIMENTO, 2004; LIMA et al., 2006).

Na curva obtida pela regressão dos parâmetros avaliados, preferencialmente para a metodologia de imersão das sementes em soluções de PEG, é possível inferir que até o potencial de -0,3 MPa ocorre condicionamento osmótico das sementes, deixando-as prontas para os eventos de germinação, enquanto na 
-0,4 MPa a restrição interferiu no seu vigor. Entretanto, observando a restrição hídrica e utilizando papel embebido com as soluções, as sementes com o passar do tempo e o aumento da restrição, sofreram redução na germinação até não se observarem eventos nos potenciais de -0,3 e 0,4 MPa.

Em alguns casos, a exposição à restrição hídrica pode comprometer o vigor das sementes quando submersas e sem aeração, já que a restrição hídrica pode-se apresentar não positiva, pois as sementes expostas a baixos potenciais osmóticos, ao passarem para a condição de plena disponibilidade de água, são prejudicadas, como verificado por Sperroto et al. (1999) em sementes de Phaseolus vulgaris L. No jenipapo, nota-se que não houve interferência no vigor das sementes, mesmo imersas por 18 dias nas soluções de politenoglicol.

Nas sementes de jenipapo, essas informações foram importantes, pois, por se tratar de espécie encontrada em regiões de mata ciliar, está sujeita a alagamentos e secas, ou seja, seus frutos estão expostos às variações climáticas que afetam os cursos d'água, o que pode comprometer a manutenção da espécie ao longo do tempo.

\section{CONCLUSÕES}

- A imersão de sementes Genipa americana L. em soluções de PEG 6000 com potencial de -0,3 MPa permite condicionamento osmótico, enquanto com 0,4 MPa interfere no vigor das sementes.

- Na restrição hídrica utilizando sementes embebidas em papel ocorre redução na germinação em função do tempo, cessando nos potenciais de 0,3 e $0,4 \mathrm{MPa}$.

- O vigor e germinação de sementes de jenipapo são afetados negativamente quando submetidas à restrição hídrica.

\section{REFERÊNCIAS}

ANDRADE, F. M. C.; CASALI, V. W. D. Plantas medicinais e aromáticas: relação com o ambiente, colheita e metabolismo secundário. Viçosa, MG: Arte Livros, 1999. 139p.

Revista Árvore, Viçosa-MG, v.35, n.2, p.213-220, 2011
ANDRADE, S. A. C. et al. Desidratação osmótica do jenipapo (Genipa americana L.). Ciência e Tecnologia de Alimentos, v.23, n.2, p.276-281, 2003.

BITTENCOURT, M. L. C. et al. Efeito do condicionamento osmótico na germinação e vigor de sementes de aspargo sob estresse hídrico e térmico. Revista Brasileira de Sementes, v.26, n.1, p.50-56, 2004.

CARVAlHO, L. M.; CASALI, V. W. D. Plantas medicinais e aromáticas: relações com luz, estresse e insetos. Viçosa, MG: Arte Livros, 1999. 148p.

CARVALHO, C. J. R. Respostas de plantas de Schizolobium amazonicum (S. parahyba var. amazonicum) e Schizolobium parahyba (Schizolobium parahybum) à deficiência hídrica. Revista Árvore, v.29, n.6, p.907-914, 2005.

COSTA, M. C. et al. Substratos para produção de mudas de jenipapo (Genipa americana L.). Pesquisa Agropecuária Tropical, v.35, n.1, p.19-24, 2005.

CRESTANA, C. S. M.; BATISTA, E. A.; MARIANO, G. Fenologia da frutificação de Genipa americana L. (Rubiaceae) em mata ciliar do Rio Moji Guaçu, SP. IPEF, n.45, p.31-34, 1992.

FERREIRA, D. F. Análises estatísticas por meio do Sisvar para Windows versão 4.0. In: REUNIÃO ANUAL DA REGIÃO BRASILEIRA DA SOCIEDADE INTERNACIONAL DE BIOMETRIA, 45., 2000, São Carlos. Anais... São Carlos: UFSCar, 2000. p.255-258.

FERREIRA,W. R. et al. Crescimento de mudas de Genipa americana L. submetidas a condições de pré-semeadura. Revista Brasileira de Biociências, v.5, n.2, p.1026-1028, 2007.

FONSECA, S. C. L.; PEREZ, S. C. J. G. A. Ação do polietileno glicol na germinação de sementes de Adenanthera pavonina L. e o uso de poliaminas na atenuação do estresse hídrico sob diferentes temperaturas. Revista Brasileira de Sementes, v.25, n.1, p.1-6, 2003. 
JELLER, H.; PEREZ, S. C. J. G. A. Condicionamento osmótico na germinação de sementes de cássia-donordeste sob estresse hídrico, térmico e salino.

Pesquisa Agropecuária Brasileira, v.38, n.9, p.1025-1034, 2003.

LABOURIAU, L. G.; VALADARES, M. E. B. On the germination of seeds Calotropis procera (Ait.) Ait.f. Anais da Academia Brasileira de Ciências, v.48, n.2, p.263-284, 1976.

LABOURiAu, L. G. A germinação de sementes. Washington: Organização dos Estados Americanos, 1983. 174p.

LIMA, J. D.; ALMEIDA, C. C.; DANTAS, V. A. V. Efeito da temperatura e dos substrato na germinação de sementes de Caesalpinia ferrea Mart. ex. Tul. (Leguminosae). Revista Árvore, v.30, n.4, p.513-518, 2006.

MAGUIRE, J. D. Speed of germination and in selection and evaluation for seedling emergence and vigor. Crop Science, v.2, n.1, p.176-177, 1962.

MICHEL, B. E.; KAUFMANN, M. R. The osmotic potential of polyethilene glycoI 6000. Plant Physiology, v.51, n.6, p.914-6, 1973.
NASCIMENTO, W. M. Condicionamento osmótico de sementes de hortaliças. Brasília: Embrapa, 2004. 12p. (Circular Técnica, 33).

ROSSETTO, C. A. V.; MINAMI, K.; NAKAGAWA, J. Efeito do condicionamento fisiológico de sementes de beterraba na emergência e na produtividade. Revista Brasileira de Sementes, v.20, n.2, p.350-355, 1998.

SILVA, A. P.; DE LIMA, C. L. C.; VIEITES, R. L. Caracterização química e física do jenipapo (Genipa americana L.) armazenado. Scientia Agricola, v.55, n.1, p.29-34, 1998.

SPEROTTO, C. C. I.; MENEZES, N. L.; STORCK, L. Desempenho de sementes e plantas de feijoeiro sob efeito do condicionamento osmótico e da aplicação de zinco. Revista Ciência Rural, v.29, n.2, p.253-257, 1999.

UNITED NATIONS CONFERENCE ON TRADE AND DEVELOPMENT - UNCTAD. Market brief in the European Union for selected natural ingredients derived from native species: Genipa americana - Jagua, huito. Holanda: UNCTAD/ BTFP, 2005. 38p. 
